\title{
LOS CLAROSCUROS DE LA JUSTICIA CONSTITUCIONAL: UN ENFOQUE COMPARADO MÉXICO Y ESPAÑA
}

The lights and shadows of Constitutional Justice: a comparative approach Mexico-Spain

MIGUEL REVENGA SÁNCHEZ Universidad de Cádiz miguel.revenga@uca.es

ROCíO GUADALUPE QUIÑONES ANDRADE IIJ-UNAM

roguquian@gmail.com

Cómo citar/Citation

Revenga Sánchez, M. y Quiñones Andrade, R. G. (2020). Los claroscuros de la justicia constitucional: un enfoque comparado México y España. Anuario Iberoamericano de Justicia Constitucional, 24(1), 51-82. doi: https://doi.org/10.18042/cepc/aijc.24.02

Resumen

El trabajo realiza una enumeración comparada de determinados aspectos de la regulación de la Suprema Corte de la Justicia de la Nación mexicana, así como del Tribunal Constitucional español, que pueden considerarse problemáticos. Problemáticos bien porque proceden de un momento histórico diferente en cuanto al significado de la Constitución y la posición de su intérprete supremo, o bien porque dan pie a prácticas aplicativas que deberían revisarse con el fin de que el sistema de control de constitucionalidad, en su conjunto, mejorara en eficiencia e incrementara su credibilidad.

\section{Palabras clave}

Suprema Corte de Justicia (México); Tribunal Constitucional (España); sistema de control de constitucionalidad. 


\begin{abstract}
This paper enlists and compares several regulative mechanisms of the Mexican Supreme Court of Justice of the Nation and the Constitutional Court of Spain, framed as inherently problematic. This consideration emanates from a contrasting historical standpoint regarding the meaning of the Constitution and the position of its supreme interpreter. These historical structures derive in a series of practices that demand a contemporary revision to improve the constitutional control system, as a whole, and to advance its credibility and efficiency.
\end{abstract}

\title{
Keywords
}

Supreme Court of Justice (Mexico); Constitutional Court (Spain); constitutional control system. 


\section{SUMARIO}

I. A MODO DE INTRODUCCIÓN: ¿̇POR QUÉ CLAROSCUROS? II. POSICIÓN INSTITUCIONAL DE LA SCJN Y DEL TC. III. DESIGNACIÓN DE LOS INTEGRANTES DE LA SCJN Y DEL TC. IV. ¿ CCÓMO SE ORGANIZA EL TRABAJO INTERNO DE LA SCJN Y DEL TC DESDE EL PUNTO DE VISTA ORGÁNICO? V. ¿ CÓMO DECIDEN «QUÉ DECIDIR» LA SCJN Y EL TC? VI. ¿̇CUÁL ES EL LUGAR DE LA JURISPRUDENCIA DE LA SCJN Y DEL TC EN EL SISTEMA JURÍDICO? VII. A MODO DE CONCLUSIÓN. Biblografía. TESIS JURISPRUDENCIALES Y ACUERDOS LEGISLATIVOS EN MÉXICO. JURISPRUDENCIA DEL TC ESPAÑOL Y DEL TEDH. ANEXo.

\section{A MODO DE INTRODUCCIÓN: ¿̇POR QUÉ CLAROSCUROS?}

Si algo caracteriza hoy a los estudios sobre el funcionamiento de la justicia constitucional, es el escepticismo que reflejan con respecto a la vigencia de los modelos clásicos de control de constitucionalidad. La contraposición entre un modelo de control difuso de impronta norteamericana, puesto en circulación a partir de Marbury (y después adormecido por espacio de décadas antes de resurgir con fuerza), y el modelo "profesoral» europeo, concebido por Kelsen sobre la base de un tribunal especializado con el monopolio de un control sobre la ley del que resultaba una especie de «legislador negativo», apenas sirven ya hoy como arquetipos o «tipos ideales» de justicia constitucional. Unos arquetipos que a menudo actúan como guías directrices de nuestra manera de contemplar una realidad compleja y llena de vericuetos. Lo que en ella se pone en juego es nada menos que el punto hasta el que estamos dispuestos a llegar cuando otorgamos a la Constitución el carácter de norma vinculante para los poderes públicos, y al constitucionalismo el de una idea fuerza de la que esperamos quizá cosas que llevan en sí mismas un fuerte potencial de conflicto: procedimientos y controles sobre el poder, pero, a la vez, realización de los derechos «en la mayor medida posible» y deberes correlativos de los gobernantes. Todo ello en el marco de una democracia que calificamos de "constitucional», quizá no tanto por el legado que el constitucionalismo nos ha ido dejando durante los dos últimos siglos como por la pluralidad de las funciones que hoy asignamos al «derecho de la Constitución»; entre ellas, y en una relación de coesencialidad, la de hacer viable la posibilidad misma de una práctica democrática. 
Ciertamente, entre el juez de la ley que actúa en salvaguarda de la supremacía constitucional y el legislador que lo hace bajo el estímulo de la legitimación proveniente del voto pueden darse tensiones y desencuentros que continúen alimentando el debate sobre la relación entre la justicia constitucional y la democracia. Pero dicha "dificultad contra mayoritaria», que en realidad no es algo que afecte solo al juez de la ley, sino al fundamento y los alcances de la jurisdicción en el Estado constitucional, nos parece que es una cuestión que ha quedado un tanto relegada con respecto a otra que es previa y aun más importante. Nos referimos a lo que pueda significar hoy la "constitucionalidad del poder", lo que es tanto como preguntarse por el lugar que ocupa la Constitución en la vida política y en la experiencia jurídica de un país determinado. Y eso, que tiene algo de contingente, en cuanto depende de la cultura política que se ha ido asentando en un «espacio» y en un tiempo concreto, es también cuestión de una buena planificación y un correcto diseño de formas y técnicas de control sobre la actuación de los poderes públicos (incluida la jurisdicción) que generen cumplimiento de la Constitución, en lugar de abrir fosos insondables entre ella y la realidad.

Son cuestiones del repertorio de problemas del constitucionalismo que pueden considerarse ya clásicas y que seguirán proporcionando todo el interés del mundo a las aproximaciones teóricas sobre la «justiciabilidad» de la Constitución, en términos generales, o desde una perspectiva apegada al análisis comparado, o "de caso» (Aragón Reyes, 2019). Lo que nosotros pretendemos hacer en las páginas que siguen es algo mucho más modesto. Pretendemos simplemente describir ciertas pautas de desarrollo del control de constitucionalidad en dos países, México y España, encuadrables en modelos diferentes de control: descentralizado y difuso el primero de ellos, con un poder judicial desdoblado territorialmente y repartido entre 32 entidades federativas, pero con un único Tribunal a la cabeza, la Suprema Corte de Justicia de la $\mathrm{Na}$ ción (SCJN), que tiene la última palabra tanto en lo que se refiere a la aplicación de la Constitución como en lo relativo a la del derecho de rango infraconstitucional (Soberanes Fernández, 1987) ${ }^{1}$. Y centralizado y con una propensión fuertemente concentrada en el caso de España, donde la función de interpretación

1 Se trata de un sistema con pluralismo constitucional estatal y, al mismo tiempo, con supremacía de la Constitución federal. En los últimos años, hay un proceso continuo de avance del control de constitucionalidad a escala local, esto es, en las entidades federadas. Así ocurre, aunque no en todas partes con igual ritmo de desarrollo, en Campeche, Chiapas, Chihuahua, Ciudad de México, Coahuila, Colima, Durango, Estado de México, Guanajuato, Guerrero, Hidalgo, Morelos, Nayarit, Nuevo León, Oaxaca, Querétaro, Quintana Roo, Sinaloa, Tabasco, Tlascala, Veracruz, Yucatán y Zacatecas. 
suprema de la Constitución se organiza sobre la base de la creación de un órgano, el Tribunal Constitucional (TC), separado de la jurisdicción ordinaria y dotado de competencias que desbordan ampliamente el control de la ley para incidir también, entre otras cosas, en la tutela de los derechos fundamentales. Esto último, por cierto, el recurso de amparo, así llamado por igual en México y en España, invita a aproximaciones comparativas y analógicas que han tenido brillantes cultivadores (Ferrer MacGregor, 2000), pero que nosotros dejaremos aquí de lado.

Lo que ha atraído nuestra atención es que, más allá de los modelos y de los sistemas de justicia o de jurisdicción constitucional, y más allá del auge que ha cobrado en las últimas décadas el derecho procesal constitucional, hay cuestiones que nos parecen determinantes para el alcance de esa «justiciabilidad» de la Constitución a la que nos venimos refiriendo ${ }^{2}$, y que tienden a plantearse indefectiblemente allí donde la Constitución aparece dotada de fuerza normativa, esto es, allí donde hay democracia constitucional y, por ende, compromiso con los derechos. Por supuesto, que un análisis a fondo de tales cuestiones requeriría mucho más espacio del que aquí disponemos. $\mathrm{Y}$ así mismo, el elenco de las cuestiones que hemos seleccionado para realizar una evaluación comparativa entre México y España, que dé alguna utilidad al empeño que ahora emprendemos, es en sí mismo discutible y podría revisarse al alza o a la baja.

En su primera acepción, que es la que se usa en la técnica pictórica, el Diccionario de la Real Academia Española de la Lengua define claroscuro como el "contraste acusado entre la luz y la sombra de un cuadro». Y es precisamente ese efecto de contraste, que se puede producir en las propias regulaciones normativas como consecuencia de sus insuficiencias o de su carácter confuso o poco sistemático, o bien al plasmarse en desarrollos o prácticas aplicativas que se aparecen como problemáticas desde el punto de vista de la eficiencia del sistema de justicia constitucional en su conjunto, el que actúa como referente del cuadro que nos proponemos trazar.

2 Empleamos, como se advierte, la expresión quizá poco ortodoxa de «justiciabilidad» de la Constitución para referirnos a la función consistente en decidir un conflicto jurídico tomado como referente principal el derecho de la Constitución, ya sea frente al legislador o, en general, frente a la actuación de los poderes públicos o incluso en los conflictos entre particulares. Cuando quien resuelve el conflicto lo hace de manera definitiva, en el sentido de que dicta una resolución contra la que no cabe recurso, estará actuando como un intérprete supremo de la Constitución, ya lo sea en su condición de órgano situado en la cúspide del Poder Judicial, como ocurre en México, ya sea en su carácter de órgano constitucional separado de este, e instituido en la Constitución para que cumpla tal cometido. 
$\mathrm{Al}$ abrigo de tal idea y con la intención de realzar los contrastes y los rasgos que caracterizan los claroscuros de uno y otro sistema, trataremos en epígrafes sucesivos la posición institucional de la SCJN y del TC (II). Plantearemos la cuestión del nombramiento de los ministros de la SCJN y de los magistrados del TC (III). Nos detendremos en la organización interna de ambos órganos (IV). Miraremos los modos mediante los cuales los órganos supremos de la «justiciabilidad» constitucional tienden a acomodar su agenda a la capacidad teórica de trabajo (V). Y analizaremos, en fin, cómo se intenta afianzar el lugar de la jurisprudencia de los supremos intérpretes en uno y otro sistema (VI).

\section{POSICIÓN INSTITUCIONAL DE LA SCJN Y DEL TC}

En línea de principio, podría decirse que el funcionamiento fluido de cualquier sistema de control de constitucionalidad se ve favorecido cuando las fuentes normativas que lo regulan se hallan establecidas en disposiciones del máximo nivel, y gozan además de un consenso político sostenido en el tiempo. Cuando se dan tales condiciones, seguramente los arreglos institucionales que propician el control consiguen estabilizarse y son percibidos como exitosos, con independencia de que el transcurso del tiempo dé razones para introducir los cambios y los retoques normativos que se consideren oportunos (Comisión de Venecia, 2017).

La regulación de la actuación de la SCJN es, por decir lo menos, barroca. Confluyen normas de variado rango que determinan aspectos específicos de la actuación de la Corte, su funcionamiento interno, sus competencias en cada uno de los procesos en los que puede intervenir, su presupuesto, la información que debe hacer pública y otras cuestiones. Sin duda, las más importantes de estas normas son, por un lado, la Constitución Política de los Estados Unidos Mexicanos, que establece en varios artículos las atribuciones y la composición de la SCJN y, de forma limitada, incluso su forma de administración; y, por otro lado, la Ley Orgánica del Poder Judicial de la Federación, en donde se desarrollan los aspectos mencionados, así como el Reglamento interno de la SCJN, en el que se detalla la organización y el funcionamiento. La posición institucional de la SCJN está firmemente anclada en el art. 94 de la Constitución, un artículo que no ha estado al margen de la tendencia hacia el «hiperreformismo» que caracteriza a la experiencia constitucional mexicana ${ }^{3}$. Las reformas han incidido

3 Hasta el momento en el que escribimos estas líneas (marzo de 2020), la Constitución Política de los Estados Unidos Mexicanos, de 1917, tiene en su haber 240 decretos de reforma, con 732 modificaciones a sus 136 artículos y disposiciones transitorias. 
en el elenco de competencias atribuidas a la SCJN, así como en la composición de la Corte y en la forma de elegir a sus ministros.

Aunque desde 1917 para acá se contabilizan hasta trece modificaciones en dicho artículo, si se considera el impacto causado por estas y las realizadas sobre el conjunto del Poder Judicial de la Federación, puede detectarse una evolución lineal hacia la configuración del SCJN como un órgano al que se le ha ido descargando paulatinamente de funciones, para permitirle centrarse en las grandes cuestiones que afectan de lleno a la justiciabilidad de la Constitución y al estatuto de los derechos humanos. Es una tendencia que se acentúa a finales de los años ochenta del siglo pasado (reforma de 1987, para acrecentar las competencias de los Tribunales Colegiados de Circuito, así como de los Juzgados de Distrito, y reforma de 1990, por la que se creó el Tribunal Electoral) y que cobra un impulso definitivo con la reforma "global» del Poder Judicial de la Federación de 1994, y la del Tribunal Electoral de 1996.

La reforma de 1994 afectó de lleno al art. 105 de la Constitución, perfilando las dos grandes funciones de la SCJN en materia de control constitucional: por un lado, las acciones de inconstitucionalidad, de naturaleza abstracta, dirigida a «cuestionar la regularidad constitucional de las normas generales emitidas por los órganos legislativos» y, por otro, las controversias constitucionales (cuyo origen data de la Constitución de 1824), por medio de las cuales la SCJN "conoce de las disputas de carácter constitucional o legal surgidas entre los órdenes normativos $\mathrm{u}$ órganos a que dan lugar el sistema federal o el principio de división de poderes» (Cossío, 2011). La trascendental reforma constitucional en materia de derechos humanos de 2011, así como la realizada simultáneamente en materia de amparo, fue también un hito decisivo en esta trayectoria, debido a que realza la posición de la SCJN como un (dialogante) intérprete supremo de la Constitución, al que las Cámaras del Congreso, así como el Ejecutivo Federal, pueden instar para que dé prioridad a la resolución de aquellos asuntos (controversias constitucionales, acciones de inconstitucionalidad y amparos en revisión) que aquellas o este consideren que revisten urgencia en razón de la afectación del «interés social» o el «orden público».

En el caso de España, configurar al TC como un órgano constitucional separado del Poder Judicial no era una opción, sino un imperativo derivado de la voluntad de conferir a la Constitución la fuerza normativa que nunca había logrado en nuestra historia. Y esto porque se consideró de manera muy plausible que asentar la Constitución y establecer un intérprete privilegiado de

Esta información ha sido obtenida en la página oficial de la Cámara de Diputados del Congreso de la Unión, disponible en el enlace: http://www.diputados.gob.mx/ LeyesBiblio/ref/cpeum_art.htm. 
ella equivalía a «enfriar» los conflictos políticos y a consolidar la democracia. El título IX de la Constitución, cuya rúbrica dice escuetamente «Del Tribunal Constitucional», precede al último de los títulos de la Constitución, el que regula la reforma, y uno y otro van de la mano como instrumentos de defensa del orden constitucional. España es en esto un caso paradigmático de recuperación de la democracia en el último cuarto del siglo Xx y de incorporación necesaria y consecuente de un modelo de justicia constitucional moldeada a imagen de los ejemplos alemán e italiano de la segunda posguerra. Aprobada la Constitución en diciembre de 1978, el Parlamento de la Primera Legislatura Constitucional (1979-1982) se puso de inmediato manos a la obra para desarrollar las previsiones del título IX, hasta el punto que la Ley Orgánica del Tribunal Constitucional (LO 2/1979, de 3 de octubre), que fue la segunda en términos absolutos de las aprobadas tras la entrada en vigor de la Constitución, permitió al Tribunal, tras la elección de los magistrados en febrero de 1980, abrir su registro y comenzar a emitir resoluciones a partir de agosto de dicho año ${ }^{4}$. Desde entonces, y en un desarrollo que no ha tenido graves sobresaltos, ha dictado miles de resoluciones en sus tres grandes ámbitos competenciales (el control de la ley, los conflictos interorgánicos o a propósito del reparto territorial del poder y la defensa en último extremo de los derechos fundamentales), las cuales conforman hoy un impresionante acervo jurisprudencial en defensa de la fórmula política, la del Estado social y democrático de derecho, establecida en la Constitución. Las diez reformas que ha tenido la Ley Orgánica del Tribunal por medio de otras tantas leyes (que fueron aprobadas en 1984, 1985, 1988, 1999, 2000, 2007,2010 y 2015) han incidido en aspectos puntuales de la configuración del Tribunal, de sus competencias y de sus reglas de funcionamiento, pero lo han hecho respetando (por lo menos formalmente) las decisiones básicas que, sobre dichas materias y sobre el estatuto de los magistrados, aparecen recogidas en la Constitución. Hay que tener en cuenta además que en 1990 el Pleno del TC adoptó el Acuerdo por el que se aprobaba el Reglamento de Organización y Personal del Tribunal, el cual también ha sido objeto de varias reformas.

4 La primera resolución fue un auto dictado en agosto de 1980 declarando la inadmisión de un amparo. Y la primera sentencia, la 1/1981, una por la que se otorgó el amparo frente a una actuación de la jurisdicción civil que había hecho dejación absoluta de sus funciones por deferencia a lo establecido en un juicio de nulidad matrimonial dirimido ante la jurisdicción eclesiástica. 


\section{DESIGNACIÓN DE LOS INTEGRANTES DE LA SCJN Y DEL TC}

No cabe duda de que la forma de nombramiento de quienes integran los órganos jurisdiccionales supremos encargados de la defensa de la Constitución es una cuestión capital. Y lo es al menos por dos razones. La primera es que nadie niega hoy que tener la última palabra sobre el significado de la Constitución — por mucho que el funcionamiento práctico de la justicia constitucional atempere hoy en bastantes de los casos la idea misma de última palabra - es un asunto que incide profundamente sobre el proceso político. La interpretación de la Constitución, y la del derecho a la luz de ella, no es política por las técnicas a través de las cuales se materializa, pero sí lo es por las consecuencias que ella puede desencadenar. La segunda razón tiene que ver con la posición institucional y la composición personal del órgano que ejerce la interpretación suprema. Cualquier sistema de justicia mínimamente evolucionado y, desde luego, todos los encuadrables en la órbita de la democracia constitucional, son sistemas comprometidos con el valor de la independencia del juez, de todo juez, y simultáneamente son sistemas que necesitan organizarse de modo tal que la interpretación jurídica no se disperse en un océano de voces discordantes, sino que aparezca como un "compacto» alumbrado por la idea de jerarquía y dotado de un punto de «cierre» con capacidad de producir, sobre la interpretación, efectos de coherencia interna y expectativas razonables de certeza. Las formas de nombramiento de los jueces varían de un sistema a otro, según las tradiciones en las que se inserten, burocrático-funcionarial, en la tradición del civil law, o bien de impronta profesionalizada (y abierta ocasionalmente a la elección popular), en la anglosajona (Serra Cristóbal, 2011); pero en cualquiera de los dos casos lo habitual es que haya unas reglas generales relativas a la selección de los jueces, y otras particulares referidas a los jueces que conforman el órgano supremo. Obviamente dicha lógica es aún más contundente allí donde hay jurisdicción constitucional de carácter especializado, como ocurre en España. Pero, también donde eso no se da, lo que importa es que la relevancia de la posición del número (siempre limitado) de jueces que están en la cúspide de la organización judicial plantea de manera particularmente intensa cuestiones de independencia e imparcialidad, pero también de legitimidad y de responsabilidad políticas, que hacen necesaria una respuesta constitucional $a d$ hoc en lo que se refiere a su nombramiento.

Veamos cómo se responde a esas exigencias en México y en España. Las reglas especiales para el nombramiento de los actualmente once ministros (y de las ministras, como señala expresamente la Constitución mexicana tras la reforma de 2019) de la SCJN se hallan en los arts. 94 a 96 de la Constitución. Según dispone el art. 95 constitucional, los requisitos para ser ministro de la Suprema Corte son: a) ser ciudadano mexicano por nacimiento, en pleno 
ejercicio de sus derechos políticos y civiles; b) tener por lo menos 35 años; c) poseer título de Licenciado en Derecho expedido por institución autorizada; d) gozar de buena reputación y no haber sido condenado por delito que amerite pena corporal de más de un año de prisión, ni por ninguno que lastime seriamente la buena fama pública; e) haber residido en el país durante los dos años anteriores al día de la designación, y f) no haber sido secretario de Estado, fiscal general de la República, senador, diputado federal, ni titular del poder ejecutivo de alguna entidad federativa, durante el año previo al día de su nombramiento. Aunque no se establece como un requisito sine qua non, la Constitución señala que se debe preferir para ocupar este cargo a aquellas personas que hayan servido con eficiencia, capacidad y probidad en la impartición de justicia o que se hayan distinguido por su honorabilidad, competencia $\mathrm{y}$ antecedentes profesionales en el ejercicio de la actividad jurídica ${ }^{5}$. Una vez nombrados, los ministros de la SCJN durarán quince años en su encargo y no pueden ser reelectos. Durante el tiempo de su encargo pueden ser removidos únicamente por incurrir en alguna de las causales que los arts. 109 y 110 de la Constitución señalan para el régimen general de los servidores públicos. La designación de los ministros, de conformidad a los arts. 76 y 96 constitucionales, se realiza por el Senado, quien los elige, previa comparecencia de los candidatos, de entre la terna que le somete el presidente de la República. Se necesita el voto de las dos terceras partes de los miembros del Senado presentes, en el plazo de treinta días, de lo contrario, esta facultad pasará al presidente de la República. Además, si la Cámara de Senadores rechazare la terna propuesta por el presidente, este deberá proponer una nueva. Y si la segunda terna es rechazada de nuevo, el presidente podrá nombrar libremente al nuevo ministro o ministra.

Este procedimiento, conforme se ha estudiado en detalle (Astudillo, 2010, y Astudillo y Estrada Marún, 2019), deja bastantes cuestiones en el aire. La primera es que la regulación bascula en exceso sobre la discrecionalidad del presidente en la elaboración de las ternas (dentro del cumplimiento de las exigencias constitucionales), conformándose además la intervención del Senado como una potestad sujeta a plazo de ejercicio perentorio y bajo la amenaza de la libre designación presidencial. La segunda cuestión relevante es que la Constitución simplemente establece que los candidatos deberán comparecer ante el Senado, pero no especifica ninguna otra cuestión, examen, entrevista

5 «Los nombramientos de los Ministros deberán recaer preferentemente — señala el artículo 95 in fine - entre aquellas personas que hayan servido con eficiencia, capacidad y probidad en la impartición de justicia o que se hayan distinguido por su honorabilidad, competencia y antecedentes profesionales en el ejercicio de la actividad jurídica». 
o mayor trámite al respecto, por lo que el procedimiento queda al albur de ulteriores desarrollos. Esta falta de concreción ha sido suplida mediante acuerdos particulares de la Cámara de Senadores, pero sin que tampoco exista al respecto un trámite parlamentario fijo y establecido con proyección permanente. Cada vez que se tiene que nombrar un nuevo integrante de la SCJN, se dicta un nuevo acuerdo, que no coincide necesariamente con lo establecido en el anterior.

De hecho, en cada una de las últimas cinco renovaciones parciales, 2012, 2015, 2018, y 2 en 2019, se han producido cambios en las «reglas del juego» que ensanchan o acortan las posibilidades de acción de los senadores e impiden, en definitiva, que el advise and consent del Senado — si se nos permite la licencia, dada la semejanza con el sistema que se sigue en los Estados Unidos- llegue a tener un sentido y alcance predeterminados. En algún momento (Acuerdo de 2015) se permitió que los integrantes de la Comisión de Justicia de la Cámara de Senadores, o incluso los del Pleno, pudieran dirigir preguntas a los candidatos integrantes de la terna, y también se contempló la posibilidad de llamar a determinados actores de la «sociedad civil» (Facultades de Derecho, Institutos de Investigación y Barras de abogados) para que formularan observaciones. Además, en el acuerdo de dicho año, más allá de la comprobación de los requisitos formales, se solicitó de forma adicional a los candidatos, su síntesis curricular, así como una serie de composiciones escritas sobre varios tópicos relacionados con la justicia constitucional, que tenían como fin examinar el conocimiento de los candidatos sobre normas constitucionales, derechos humanos, jurisprudencia, derecho internacional, así como fijar el criterio que seguirían en la resolución de conflictos ante el máximo tribunal. Sin embargo, los tres acuerdos aprobados durante la actual presidencia de López Obrador han supuesto, con relación al del año 2015, una modificación a la baja, pues se han eliminado los requisitos referentes a las composiciones escritas, incluyendo la presentación de la síntesis curricular a cargo del candidato. Estos cambios denotan la gran discrecionalidad que existe en el nombramiento de los integrantes del máximo tribunal de justicia mexicano, que puede llegar a estar conformado por personas no idóneas para una responsabilidad de tal envergadura, ya que las formalidades y requisitos adicionales en el procedimiento pueden variar de una legislación a otra, de todo lo cual se infiere que la última palabra en la designación tiende a depender de las conveniencias políticas del ejecutivo federal.

Es interesante destacar que, a raíz de la "gran reforma» de 1994, se estipuló que la designación de los ministros de la SCJN se realizaría con arreglo a un sistema establecido de escalonamiento temporal, a cuyo efecto en aquel momento se dispuso que a partir de 2003 (y sucesivamente en 2006, 2009 y 2012) habría que renovar a dos ministros y en 2015 a los tres restantes, como 
efectivamente se hizo. Esto nos parece una buena manera de conjugar los objetivos de continuidad del trabajo de la SCJN con el de evitar renovaciones colectivas que perjudican la causa de la transparencia, así como una llamada de atención de la opinión pública sobre la trascendencia de la renovación. Y aunque la doctrina no ha dejado de clamar por la elaboración de normas de rango suficiente que proporcionen estabilidad y mejoren el sistema de nombramiento, ese es un dato que nos parece relevante a la luz de los problemas que se han originado en España con motivo de la renovación de los magistrados del TC.

La Constitución española regula en su art. 159, que es el que abre el título dedicado al Tribunal Constitucional, la composición de este, así como el sistema de nombramiento y los rasgos básicos del estatuto de los magistrados. Estos, en número de 12, serán nombrados entre «Magistrados y Fiscales, Profesores de Universidad, funcionarios públicos y Abogados», todos los cuales han de ser «juristas de reconocida competencia» y contar con quince años al menos de ejercicio profesional. Su nombramiento, que expide el rey, se produce por un período de 9 años y su elección se reparte así: 4 por el Congreso, 4 por el Senado (en los dos casos por mayoría reforzada de tres quintos), 2 por el Gobierno y 2 por el Consejo General del Poder Judicial. Una lógica que responde a la idea de la participación de los tres poderes «clásicos» del Estado (aunque el Consejo General del Poder Judicial, que es el órgano de gobierno de los jueces, no ejerce jurisdicción), en lugar de concentrar en el Parlamento la elección de todos, como ocurre en bastantes sistemas europeos y del ámbito iberoamericano (Nogueira Alcalá, 2019). Esto se completa con una regla relativa a la renovación del Tribunal (art. 159.3) en la que se estatuye que se realizará por terceras partes cada tres años, una estipulación que la propia Constitución completó a través de una disposición transitoria en la que se decidió que los magistrados propuestos por el Gobierno y por el Consejo General del Poder Judicial conformarían uno de los tres grupos de cuatro magistrados a efectos de la renovación y se previó la celebración de sendos sorteos a los tres y a los seis años desde la primera elección para decidir cuál de los grupos habría de renovarse ab initio.

Las previsiones constitucionales son sobre esto, por así decir, "cartesianas». Para conjurar el riesgo de la elección de magistrados «de partido», mayorías parlamentarias reforzadas; y para lograr una renovación periódica ordenada y por turnos, la confección de tres grupos de cuatro magistrados para ser renovados cada tres años al término de sus nueve años de mandato. La cuestión es que con frecuencia la vida real no acaba de acomodarse a la intención de los autores de las leyes y así ha ocurrido en esto como consecuencia de dos factores que han acabado por poner en entredicho el acierto de los mismos al enfrentarse a este importante asunto. El primero de los 
factores tiene que ver con un mal que afecta a menudo al funcionamiento de las democracias. Consiste en actuar de tal manera que se transmita la impresión de que la "partitocracia» puede más que la «meritocracia»; lo que trasladado a este ámbito significa "reparto» de cuotas entre los partidos, o lottizzazione por usar el vocablo italiano. En una famosa sentencia, la STC 108/1986, el Tribunal Constitucional advirtió que había ámbitos de decisión política que, por su relevancia, por así decir «institucional», deberían quedar al margen de la lógica de funcionamiento del Estado de partidos ${ }^{6}$. La sentencia se refería al cambio introducido por el legislador en el modo de elección de los miembros del Consejo General del Poder Judicial, pero esa consideración podría aplicarse perfectamente a la renovación de los magistrados del TC. Porque lo que ha venido ocurriendo es que la exigencia de mayoría de tres quintos no ha operado como una regla que propicie el acuerdo interpartidista sobre los candidatos más idóneos, sino, lisa y llanamente, reparto de cuotas entre los dos grandes partidos tradicionales. Con ello no estamos insinuando que, más allá del cumplimiento de los requisitos de mínimos que se establecen en la Constitución, resulta pertinente la sospecha sistemática sobre las cualidades profesionales de quienes han accedido al Tribunal previa la elección del Congreso y del Senado; ni tampoco sugerimos que el comportamiento de los magistrados en el ejercicio del cargo pueda presentarse como un trasunto de la voluntad de los partidos que impulsaron la candidatura. Las pautas de conducta en el desempeño de la jurisdicción resultan siempre notoriamente más complejas de lo que pretenden las etiquetas magistrados «conservadores» frente a magistrados "progresistas». Pero dicho esto, es indudable que un sistema que favorece la negociación entre bambalinas de los partidos, en lugar de

6 Vale la pena reproducir textualmente el párrafo en cuestión de la referida sentencia: «Ciertamente, se corre el riesgo de frustrar la finalidad señalada de la Norma constitucional si las Cámaras, a la hora de efecturar sus propuestas, olvidan el objetivo perseguido y actuando con criterios admisibles en otros terrenos, pero no en éste, atiendan sólo a la división de fuerzas existente en su propio seno y distribuyen los puestos a cubrir entre los distintos partidos, en proporción a la fuerza parlamentaria de éstos. La lógica del Estado de partidos empuja a actuaciones de este género, pero esa misma lógica obliga a mantener al margen de la lucha de partidos ciertos ámbitos de poder y entre ellos, y señaladamente, el Poder Judicial. La existencia y aun la probabilidad de ese riesgo, creado por un precepto que hace posible, aunque no necesaria, una actuación contraria al espíritu de la Norma constitucional, parece aconsejar su sustitución, pero no es fundamento bastante para declarar su invalidez, ya que es doctrina constante de este Tribunal que la validez de la ley ha de ser preservada cuando su texto no impide una interpretación adecuada a la Constitución». 
propiciar la comparecencia y comprobación de las cualidades de los candidatos con «luz y taquígrafos», no es un buen sistema.

El segundo factor de descrédito del sistema de nombramiento está estrechamente relacionado con el que acabamos de resumir, y tiene una doble proyección. La más evidente es la que proviene de los retrasos que se han originado en la renovación de los magistrados correspondientes a los grupos de las Cámaras, retrasos que, en el período comprendido entre 2007 (en el que correspondía elegir al Senado, aunque no lo hizo hasta 2010) y 2010 (en el que correspondía elegir al Congreso, aunque en realidad no lo hizo hasta 2012), alcanzaron las características de un problema endémico que afectó gravemente a la legitimidad del Tribunal. La Ley Orgánica del TC (art. 17.2) contempla la prórroga automática de ejercicio de la función por parte de los magistrados salientes hasta que son sustituidos, pero, con independencia de ello, y en el contexto de un momentum delicado de la vida del Tribunal, en el que tenía pendiente de decidir sobre la constitucionalidad del nuevo Estatuto de Cataluña, unos retrasos tan dilatados causaron un efecto demoledor ${ }^{7}$. Pero es que, además — segunda proyección—, el sistema de renovación escalonada por grupos de cuatro solo podría funcionar en condiciones de coincidencia absoluta de los momentos iniciales y finales del encargo de todos y cada uno de los cuatro magistrados de cada grupo. Como ese no ha sido nunca el caso, pues desde el principio hubo dimisiones o fallecimientos, así como retrasos puntuales en los nombramientos de magistrados que hacían inviable la cadencia trienal preestablecida y la coincidencia temporal, en el año 2010 se introdujo una reforma en la Ley Orgánica para disponer (art. 16.5) que «si hubiese retraso en la renovación por tercios de los magistrados, a los nuevos que fuesen designados se les restará del mandato el tiempo de retraso en la renovación». Se ha dado, por tanto, primacía absoluta a la regla de la renovación por tercios, situándola por encima de otra regla constitucional de contenido perfectamente claro: la que estatuye un mandato de 9 años para los magistrados, algo que, para buena

7 La sentencia sobre el Estatuto —STC 31(2010)— se haría pública afínales del mes de junio de dicho año. Hay que añadir que, por lo que se refiere al Senado, un factor que coadyuvó a la demora fue la reforma introducida en 2007 en la Ley Orgánica del TC, por medio de la cual se previó (art. 16.1) la participación de los Parlamentos de las Comunidades Autónomas en el proceso de designación, mediante la elevación al Senado de propuestas de candidatos. Recurrido este y otros aspectos de la reforma ante el TC, este resolvió (SsTC 49 y 101 de 2008) que en último extremo es el Senado el que tiene la potestad de elegir, por lo que puede apartarse de las propuestas (o suplirlas) formuladas por los Parlamentos autonómicos. Sobre esta cuestión, véase Urías, 2010. 
parte de la doctrina especializada, no se ajusta a la Constitución (Fernández Farreres, 2015; Estrada Marún, 2017). De ahí que esa misma doctrina haya postulado mejoras del sistema, como la de trasladar al Pleno del TC la facultad de selección si en el plazo de tres meses desde que la elección debió producirse las Cámaras son incapaces de realizarla, o bien dar un vuelco al sistema para propiciar la elección individualizada de magistrados a medida que el mandato de los mismos llega a los 9 años (en el mismo sentido, también, Ferreres Comella, 2011). Y esto porque se estima, con toda razón, que la designación individualizada atrae la atención de la opinión pública y potencia las posibilidades de transparencia del proceso, y control sobre el mismo, objetivos que la actual regulación está muy lejos de cumplir ${ }^{8}$.

\section{IV. ¿̇CÓMO SE ORGANIZA EL TRABAJO INTERNO DE LA SCJN Y DEL TC DESDE EL PUNTO DE VISTA ORGÁNICO?}

La SCJN es el máximo tribunal constitucional de México, por lo cual se encarga de ejercer un control constitucional y convencional a través de un conjunto de procedimientos, de los cuales, sin duda, los más trascendentales son las controversias constitucionales, las acciones de inconstitucionalidad, los amparos en revisión de casos trascendentales, los incoados en base a la facultad de atracción en el caso de amparos que tengan una trascendencia que beneficie a la sociedad, y la resolución de contradicción de tesis. Hoy en día, la tarea de control constitucional no es, sin embargo, la única función de la corte suprema, ya que también conoce de otros casos que no implican propiamente un control constitucional, como quejas, impedimentos, asuntos administrativos internos y muchos otros que llegan a sus estrados todos los años. Estas cargas constituyen parte de una competencia residual que, precisamente en estos momentos, el Congreso de la Unión discute eliminar, para dar paso a la conversión de este órgano, en un verdadero tribunal constitucional ${ }^{9}$. Esta

8 El art. 16.2 de la Ley Orgánica dispone (tras la reforma de 2007) la comparecencia de los candidatos propuestos por las Cámaras ante las correspondientes comisiones, pero hasta el momento no es exagerado decir que la previsión ha pasado "sin pena ni gloria», un simple trámite del procedimiento que no ha tenido mordiente alguna desde el punto de vista de lo que se puede esperar de una actividad de control digna de tal nombre.

9 El 12 de febrero de 2020, el presidente de la República envió a la Cámara de Senadores una propuesta de reforma integral del Poder Judicial de la Federación, que, de aprobarse, consolidaría a la SCJN como un verdadero Tribunal Constitucional. Esta propuesta se considera un hecho histórico, ya que fue elaborada por el mismo Poder 
reforma, de aprobarse, será fundamental para la reinvención de la SCJN como un genuino órgano jurisdiccional de control de constitucionalidad liberado de tareas que carecen de mordiente desde tal punto de vista, y que sobrecargan y ralentizan su actuación.

La SCJN se compone de once ministros y funciona en Pleno, donde actúan todos los ministros presididos por su presidente, o en Salas, integradas por cinco ministros cada una, en donde uno de los ministros asume el rol de presidente de la Sala. El presidente de la SCJN permanece en su encargo cuatro años y no participa en las deliberaciones de las Salas. El nombramiento de Presidente de las Salas es de dos años. La SCJN, reunida en Pleno o Salas, sesiona dos veces al año. El primer periodo comienza el primer día hábil del mes de enero y se extiende hasta el último día hábil de la primera quincena del mes de julio, y el segundo periodo comienza el primer día hábil del mes de agosto y dura hasta el último día hábil de la primera quincena del mes de diciembre. El Pleno puede sesionar con siete integrantes, a menos que el asunto tratado verse sobre controversias constitucionales, acciones de inconstitucionalidad o recursos de apelación en contra de sentencias de jueces de distrito en donde la federación sea parte o en cuestiones que por su interés y trascendencia así lo ameriten, en las que tendrán que estar presentes ocho miembros. Las Salas pueden sesionar con cuatro ministros presentes.

Las facultades que tiene el Pleno de la SCJN son muchas, e incluso se podría afirmar que hasta cierto grado son difusas, debido a que, si bien cuenta con potestades que la ley especifica claramente, también se acude a este máximo tribunal en otros asuntos en los que a veces no se sabe cómo resolver o quién es el órgano facultado. Las potestades más relevantes del Pleno son, entre otras, las controversias constitucionales y las acciones de inconstitucionalidad. Para resolver este tipo de casos, la Subsecretaría General de Acuerdos cuenta con una sección de trámite especializada en su resolución.

Judicial. Los puntos álgidos de la propuesta van en dos sentidos. Por una parte, se pretende eliminar cargas de trabajo que no tienen que ver propiamente con la defensa de la Constitución Federal, y, por otro lado, se propone dotar a este órgano máximo de mayor discrecionalidad en cuanto al conocimiento de los amparos y amparos en revisión. Además, se propone eliminar la jurisprudencia por sustitución y modificar la creada mediante reiteración, con el fin de que todas las decisiones de la SCJN votadas por una mayoría calificada sean de obligatorio cumplimiento para los órganos inferiores. En cuanto a las controversias constitucionales, en las que antes la SCJN analizaba tanto la legalidad como la constitucionalidad de los actos y normas, se propone eliminar el estudio de la legalidad, para evitar distraer al Tribunal de su tarea fundamental: la defensa de la Constitución. 
El Pleno cuenta, además, con la facultad de conocer los amparos en revisión sobre cuestiones constitucionales trascendentales, por ejemplo, aquellos en los que sobrevenga un problema de inconstitucionalidad de una norma general, contradicciones de tesis o incidentes por incumplimiento de las sentencias por las autoridades responsables en amparo. Está autorizado para determinar, a través de acuerdos generales, la competencia por materia de cada una de las Salas y la distribución de los asuntos que estas conozcan, y remitir para su resolución los asuntos de su competencia a las Salas, o bien a los Tribunales Colegiados de Circuito, y así lo hace con frecuencia a fin de liberarse del exceso de carga de trabajo y con vistas a la pronta resolución de los expedientes. Tiene otras facultades atípicas, que son las que se analizan en los asuntos denominados «varios». En estos asuntos se agrupan las consultas del presidente al Pleno y otras competencias que no tienen una denominación específica en la ley. Como se puede apreciar, las competencias de la SCJN, incluso las más trascendentes, son demasiadas, lo que, en ocasiones, hace que las resoluciones de asuntos sobre control constitucional se demoren años, impidiendo que se brinde una justicia expedita.

Una de las mayores controversias que se tiene en la SCJN es la designación de su personal alterno. La SCJN conforma, como decimos, una organización burocrática inmensa que cuenta con un gran número de integrantes que coadyuvan en la impartición de justicia en auxilio de los ministros. Este personal es elegido de forma discrecional por el ministro presidente y por el resto de los integrantes del máximo tribunal, sin que exista prácticamente ningún filtro o condición para su contratación, salvo el hecho de que sea presupuestariamente viable. El proyecto de presupuesto de la SCJN es elaborado anualmente por su presidente y remitido al Congreso de la Unión para agregarse al Presupuesto de Egresos de la Federación.

Además de actuar en Pleno o en Salas, cada uno de los ministros integra una ponencia. El Presidente de la Corte puede turnar expedientes que considere dudosos o trascendentes a los ministros ponentes con el fin de que elaboren un proyecto de resolución y lo pongan a consideración de la SCJN y se resuelva el trámite. Cada ponencia se encuentra integrada por su propio personal, incluyendo secretarios de Estudio y Cuenta que son nombrados directamente por los ministros ponentes. La LOPJF establece que, para ocupar este cargo, se exigirá que, cuando menos, dos terceras partes de las plazas que corresponden a cada ministro sean ocupadas por personas que hayan desempeñado durante dos años o más los cargos de secretario de Tribunal de Circuito o secretario de Estudio y Cuenta de las Salas Regionales del Tribunal Electoral del Poder Judicial de la Federación o secretario de Juzgado de Distrito. No existe un número determinado de secretarios de Estudio y Cuenta, ya que cada ministro tiene un presupuesto y un número de plazas y la potestad 
de decidir cómo lo distribuye. A finales de 2018, la SCJN contaba con 86 secretarios de Estudio y Cuenta y 40 adjuntos. Esta forma de elegir al personal del máximo tribunal mexicano, que en otros países resultaría inaudita, provoca que una parte muy importante de su personal pueda ingresar sin ninguna experiencia jurisdiccional previa, lo que constituye una de las principales debilidades de la SCJN, por lo que se necesita un cambio profundo, en el que se determinen mayores requisitos y filtros para poder formar parte de los servicios técnicos de apoyo.

En el caso del Tribunal Constitucional español, la estructura interna se caracteriza por una tripartición entre el Pleno (de doce magistrados), dos Salas (de seis magistrados) y cuatro secciones con tres magistrados cada una de ellas. Aunque la LOTC otorga amplias atribuciones al Pleno para avocar o delegar asuntos (sobre todo cuando se trata de aplicar jurisprudencia consolidada), podría decirse que el Pleno es competente para decidir sobre el control de la ley, ya sea en vía principal a través del recurso de inconstitucionalidad, ya sea en vía incidental cuando así se lo plantean los jueces de la jurisdicción ordinaria. El Pleno conoce además de los asuntos que afectan al reparto territorial del poder: conflictos de competencias entre el Estado y las comunidades autónomas (o a la inversa) y conflictos en defensa de la autonomía local. Las Salas son competentes para resolver los recursos de amparo; y las Secciones deciden sobre si estos últimos deben ser o no admitidos a trámite.

Sobre la posición del presidente del tribunal, la Constitución determina la duración de su mandato (tres años) y reserva a los magistrados del propio tribunal la facultad de elegirlo; la Ley Orgánica (art. 9) especifica el sistema: mayoría absoluta en primera votación y mayoría simple en segunda. Por su parte, en el art. 15 de la misma ley puede verse el núcleo de las funciones representativas y organizativas que ostenta, pero lo que la ley no deja ver es lo que nos parece que tiene más importancia: nos referimos a la capacidad del presidente para dirigir las deliberaciones del Pleno y, de manera especial, la que se refiere al dominio del presidente sobre la agenda del Pleno. Ambas cosas resultan capitales y guardan una relación que no siempre se advierte. El modus operandi para la resolución de los asuntos que ingresan en el Registro, cuando son competencia del Pleno (digamos, por ejemplo, un recurso o una cuestión de inconstitucionalidad, o bien un conflicto de competencias), conlleva la designación de un ponente que es el magistrado a quien corresponde elaborar el proyecto de resolución que es presentado ante el Pleno para debate. En un mundo ideal, el momento del debate del asunto por el Pleno debería venir predeterminado por los plazos procesales que la ley prevé para dictar sentencia en cada tipo de recurso: 30 días como máximo desde que expira el plazo para formular alegaciones tanto en el recurso como en la cuestión. Pero dicho plazo taxativo para la expresión del parecer del Tribunal resulta, en el caso del 
Tribunal Constitucional y, en general, en el de todos los tribunales, la quimera de paradójicos efectos que tantas veces se señala: los plazos procesales son de riguroso cumplimiento para todas las partes, menos para el tribunal. Efecto de ello es que el horizonte temporal desde que se presenta un recurso hasta que se notifica la sentencia siempre es incierto e indeterminable; con la consecuencia de que los retrasos y las esperas para conocer la respuesta del Tribunal en asuntos que pueden resultar de gran relieve público llegan a ser llamativos. Por poner un ejemplo: el recurso de inconstitucionalidad contra la ley del año 2010 que alteró el sistema de reconocimiento del derecho a la interrupción del embarazo, desde uno basado en indicaciones a otro que combina indicaciones y plazos - es libre durante las primeras 14 semanas de gestación-, continúa a fecha de hoy (es decir, más de diez años después) pendiente de sentencia. Las libérrimas atribuciones del Tribunal para establecer prioridades temporales en función de «jerarquías» de importancia o urgencia de los asuntos que solo a él compete establecer resaltan, en definitiva, su independencia, pero tienen al mismo tiempo un potencial perturbador sobre la idea de neutralidad con respecto a intereses políticos circunstanciales $\mathrm{o}$ «de parte».

\section{V. ¿̇CÓMO DECIDEN «QUÉ DECIDIR» LA SCJN Y EL TC?}

Todos los asuntos que lleguen a la SCJN y se encuentren estipulados en la legislación deben ser conocidos por esta, salvo dos excepciones. La primera es la facultad de atracción establecida en las fracciones V y VIII del art. 107 constitucional (Cabrera, 1990). La segunda se refiere a la posibilidad de remitir los asuntos a los Tribunales Colegiados de Circuito para su conocimiento y resolución con el fin de liberar de carga de trabajo a la SCJN y que el asunto sea resuelto con mayor prontitud.

La facultad de atracción se considera una parte inherente a la evolución de la SCJN. Esta, en ejercicio de su carácter de órgano constitucional, tiene la potestad de atraer a sus estrados los asuntos que considere de una relevancia jurídica y constitucional fundamental (Suárez, 2017). Según establece la Constitución, la Suprema Corte puede, de oficio, o a petición fundada del correspondiente Tribunal Colegiado de Circuito, del Fiscal General de la República —en los asuntos en que el Ministerio Público de la Federación sea parte- o del Ejecutivo Federal, conocer de los amparos directos y amparos en revisión que, por su interés o por su trascendencia, lo ameriten. La propia SCJN se ha encargado de establecer que la importancia y trascendencia de un caso, para ejercer la facultad de atracción, se satisfacen cuando la solicitud se realiza con el fin de integrar jurisprudencia por reiteración, o bien cuando la problemática planteada implica el análisis de preceptos constitucionales y 
legales que suponga la fijación de un criterio jurídico trascendental para casos futuros. En 2014 la Sala Primera determinó que para que un determinado asunto cumpla con el requisito de «interés» o «importancia», se requiere que del estudio del mismo se advierta una circunstancia relacionada con los siguientes casos: a) la posibilidad de una afectación grave en el patrimonio o las finanzas públicas; b) la posibilidad de que se perjudiquen áreas o sectores de importancia económica y social para el país; y c) el hecho de que la resolución del asunto haya sufrido una demora prolongada, que pueda causar una afectación del derecho a la justicia de las partes contrincantes, en relación con la obligación de las autoridades jurisdiccionales competentes de otorgar una solución a la controversia en un tiempo o plazo razonable. Por otro lado, como ya dijimos, el art. 94 de la Constitución faculta al Pleno de la SCJN para delegar en los Tribunales Colegiados de Circuito aquellos asuntos en los que ya hubiera establecido jurisprudencia o, en general, los que la propia Corte determine de cara a una mejor procura de justicia.

A pesar de ello, la carga de trabajo de la SCJN es bastante abrumadora, tal y como puede observarse en la tabla 1 correspondiente a los asuntos resueltos por la SCJN en el año 2019, disponible en el Anexo de este artículo.

En el caso del TC español, el "caballo de batalla» en cuanto al ajuste entre la capacidad de resolver y el ritmo de ingreso de asuntos en el registro se ha localizado desde siempre en el Recurso de Amparo. Es lógico que sea así, por cuanto la legitimación potencial para recurrir en amparo es «universal» por contraste a lo limitada que resulta en los demás ámbitos de trabajo del Tribunal. Hay que tener en cuenta además que, dentro de la jerarquía que caracteriza el sistema de reconocimiento de los derechos en España a los efectos del amparo, el de obtener una tutela judicial efectiva cae de lleno dentro de la órbita de máximo grado de protección. Ha ocurrido así que, desde los albores de la actuación del Tribunal, el amparo actuó como la instancia de control, en manos del TC, para medir el grado de cumplimiento de la Constitución en el desempeño de la función jurisdiccional por parte de los jueces ordinarios. Los efectos positivos que esto pudo tener desde el punto de vista de la transformación en sentido garantista del proceso, así como para mostrar al juez ordinario el modo de leer el derecho en consonancia con los imperativos de respeto a los derechos fundamentales y la supremacía de la Constitución, se vieron empañados por la inmoderada propensión de los litigantes a desvirtuar la prístina naturaleza del amparo constitucional para convertirlo en una última instancia de carácter rutinario. Es una cuestión bien conocida en los sistemas que disponen de jurisdicción constitucional especializada con acceso directo de los justiciables en defensa de sus derechos. Y aunque no se llame así, suele resolverse aplicando fórmulas que caminan en la dirección del certiorari estadounidense, es decir, en la de acentuar la discrecionalidad del Tribunal 
para trazar la barrera entre los asuntos que tienen importancia como para justificar una consideración a fondo de los mismos, y aquellos otros que no la tienen, sin que sea sencillo estatuir con carácter general y uniforme cuándo se está en presencia de uno u otro caso.

En España, el expediente para establecer dicha barrera consistió desde el principio en establecer un trámite de admisión de los amparos que permitía a las Secciones la desestimación a limine (rectius: la no admisión a trámite) por una simple providencia. Y esta fórmula recibió en 2007 un impulso decisivo con la reforma del art. 50 de la Ley Orgánica del Tribunal, mediante la cual se estableció taxativamente que quienes recurren ante el Tribunal no solo han de aducir la vulneración de derechos amparables, sino justificar la «especial trascendencia constitucional» del asunto sobre el que versa el recurso. Sobre este giro legislativo que provoca una acusadísima objetivación del recurso de amparo en detrimento de su vertiente subjetiva o «reaccional» se han vertido abundantes críticas, la mayor parte de ellas denunciando que el realismo de lo posible ha desvirtuado, hasta hacerlo irreconocible, el diseño constitucional del amparo (por todos, Morales Arroyo et al., 2014). El Tribunal Europeo de Derechos Humanos tuvo ocasión de pronunciarse sobre el particular en una sentencia que vino a actuar como una especie de control de convencionalidad (medido a la luz de las exigencias del recurso efectivo de los arts. 6 y 13 del Convenio) sobre la mencionada reforma legislativa del año $2007^{10}$. Con el argumento de la libertad para configurar razonablemente los requisitos de acceso a los recursos y, en especial, tratándose de uno de naturaleza extraordinaria y subsidiaria, como era el caso, el TEDH refrendó la reforma. Y aunque es pertinente reconocer que el TC viene realizando un cierto esfuerzo argumental para poner de manifiesto qué es lo que merece, según él, ser considerado como de especial trascendencia, lo cierto es que tenemos aquí un ámbito que resulta esquivo, precisamente allí donde la jurisdicción constitucional está conectada de manera más directa con la pluralidad de lecturas e interpretaciones de la Constitución por parte de la comunidad jurídica ${ }^{11}$. El amparo continúa

10 El asunto es Arribas Antón contra España (Demanda 16563/11) y la sentencia (de la Sección Tercera del TEDH) lleva fecha de 20 de enero de 2015.

11 La sentencia clave a estos efectos propedéuticos sobre lo que el TC considera de especial trascendencia es la 155/2009. En ella el tribunal llega al punto de establecer un elenco de supuestos en los que cabría apreciarla; entre ellos, los que le sirven para modificar su propia doctrina, los que denotan tensión interpretativa entre esta última y la de la jurisdicción ordinaria, o bien entre ella y las de la jurisprudencia europea, así como los asuntos con un acusado relieve polémico de alcance general como (dice el TC) los amparos en materia electoral o parlamentaria. La enumeración tiene de todos modos un carácter meramente ejemplificativo. 
siendo, por lo demás, la competencia situada a la cabeza de la carga de trabajo del Tribunal, como se comprueba con una ojeada a los últimos datos disponibles que corresponden igualmente a 2019 (tabla 2 del Anexo).

\section{VI. ¿̇CUÁL ES EL «LUGAR» DE LA JURISPRUDENCIA DE LA SCJN Y DEL TC EN EL SISTEMA JURÍDICO?}

La jurisprudencia constituye una herramienta indispensable en la aplicación de ley, tiene una función unificadora de criterios y generadora de pautas de conducta de naturaleza cuasi normativa. La SCJN ha definido a la jurisprudencia como «la interpretación de la ley, de observancia obligatoria, que emana de las ejecutorias que pronuncia la Suprema Corte de Justicia de la Nación funcionando en Pleno o en Salas, y por los Tribunales Colegiados de Circuito» (Tesis de jurisprudencia IX.1o.71, 2003). Además, ha establecido que la jurisprudencia puede ser confirmatoria, supletoria e interpretativa. Mediante la jurisprudencia confirmatoria se ratifica lo establecido en la ley; a través de la supletoria se colman los vacíos legales, creando una norma que la complementa; y la interpretativa brinda una explicación de la norma poniendo de manifiesto el pensamiento del legislador, esta última es la más común (Castellanos Madrazo, 2014).

La jurisprudencia se crea a través de las resoluciones de los juicios de amparo, de las controversias constitucionales, de las acciones de inconstitucionalidad y de las contradicciones de tesis, pero no todas ellas constituyen jurisprudencia de forma inmediata. A este respecto, la Ley de Amparo señala en sus arts. 215 y siguientes que la jurisprudencia se crea a través de reiteración de criterios, por contradicción de tesis y por sustitución. La jurisprudencia por reiteración la puede establecer únicamente la SCJN, en Pleno o en Salas y los Tribunales Colegiados de Circuito y se establece cuando se sustente un mismo criterio en cinco sentencias no interrumpidas por otra en contrario, resueltas en diferentes sesiones, por una mayoría de al menos ocho y cuatro votos respectivamente. Las mismas reglas rigen cuando se trata de los Tribunales Colegiados, pero en este caso la votación debe ser unánime (Jurisprudencia 2a./J. 11/2002, 2002).

La jurisprudencia por contradicción se establece por el Pleno o las Salas de la SCJN y por los Plenos de los Tribunales de Circuito. A través de este tipo de jurisprudencia se dilucidan los criterios discrepantes sostenidos entre las Salas de la SCJN, o entre los Plenos de Circuito y/o los Tribunales Colegiados, en los asuntos resueltos por estos anteriormente. Cuando han sido sentados dos criterios relevantes y se han hecho tesis jurisprudenciales que se contraponen, a través de este procedimiento se puede decidir cuál es el criterio que 
prevalece adhiriéndose a alguno de ellos, sustentando uno diverso o declarando inexistente o sin materia la contradicción, a través de la mayoría de votos del órgano que resuelva. Pese a ello, los asuntos ya resueltos no se ven afectados.

La jurisprudencia por sustitución se refiere a la evolución de las interpretaciones con el paso del tiempo, es decir, la jurisprudencia por reiteración o contradicción que puede ser sustituida con el fin de incluir criterios más amplios, protectores de derechos humanos o apegados a la nueva legislación. Solo la SCJN puede decidir la sustitución de una jurisprudencia en Pleno o en Salas y para ello se requieren ocho y cuatro votos respectivamente (López Benítez, 2017).

Toda jurisprudencia es obligatoria de conformidad a los arts. 94 constitucional y 217 de la Ley de Amparo. Este último determina que la jurisprudencia establecida por la SCJN, en Pleno o en Salas, es obligatoria con carácter general y para estas últimas tratándose de la que decrete el Pleno. Además, se establece un listado de los órganos jurisdiccionales obligados que son los Plenos de Circuito, los Tribunales Colegiados y Unitarios de Circuito, los Juzgados de Distrito, los Tribunales Militares y Judiciales del orden común de los Estados y del Distrito Federal, así como los Tribunales Administrativos y del Trabajo, locales o federales. Es decir, todas las autoridades jurisdiccionales o administrativas con actividad jurisdiccional. Por su parte, la jurisprudencia que establezcan los Plenos de Circuito y los Tribunales Colegiados de Circuito es obligatoria para las autoridades inferiores jurisdiccionales y administrativas con actividad jurisdiccional que se ubiquen dentro del mismo circuito.

Otra forma de crear jurisprudencia es a través de la llamada declaratoria general de inconstitucionalidad (Tesis de jurisprudencia 2a. XXIII/2019, 10a). La SCJN, reunida en Pleno o en Salas, puede llevar a cabo esta declaratoria cuando en dos amparos en revisión resueltos de forma consecutiva se haya establecido que una norma general es inconstitucional, o bien cuando se haya creado jurisprudencia por reiteración en el mismo sentido. Aunque solo la SCJN puede crear este tipo de jurisprudencia, los Plenos de Circuito pueden instar a la SCJN a iniciar este proceso, fundamentándose en la expedición de jurisprudencia que ha establecido que una norma es inconstitucional. Una vez iniciado este proceso, se deberá informar a la autoridad emisora de la norma. Si transcurren 90 días naturales sin que el legislador proponga la reforma de la legislación inconstitucional, la SCJN emitirá, por mayoría de ocho votos, la declaratoria general de inconstitucionalidad, que tiene efectos erga omnes.

La jurisprudencia puede ser interrumpida, y por lo tanto deja de ser obligatoria, cuando se pronuncie otra en contrario. En la jurisprudencia posterior se deberá expresar las razones en las que se apoye la interrupción. En este caso, la jurisprudencia anterior se considerará superada. Cuando el Tribunal Electoral emita una tesis sobre la inconstitucionalidad de una norma o acto de autoridad 
o bien interprete un precepto constitucional que pudiere ser contradictorio a los criterios establecidos por la SCJN, de conformidad a la Constitución, este órgano supremo será el encargado de realizar el procedimiento de contradicción de tesis correspondiente para determinar cuál es el que prevalece.

En abierto contraste al caso mexicano, que se caracteriza, como vemos, por el acusado esfuerzo dirigido a racionalizar cómo se crea jurisprudencia, cuáles son los tipos de ella y cuál su alcance en cada uno de los casos, la consideración del valor de la jurisprudencia en el derecho español es tributaria de un doble orden de factores. En primer lugar, del punto de vista tradicional, anclado en el positivismo de la más rancia estirpe cuyo influjo se deja sentir en el Código Civil, y no en cualquier parte del mismo, sino en su mismo punto de arranque, precisamente allí donde se indican, para general conocimiento, las fuentes del ordenamiento jurídico: ley, costumbre y principios generales del derecho. Con respecto a ellos, la jurisprudencia —señala el art. 1.6 del Código Civil- «complementará el ordenamiento jurídico con la doctrina que, de modo reiterado, establezca el Tribunal Supremo» al interpretarlos y aplicarlos. La visión legis-céntrica determina monopolio para la creación de la jurisprudencia en la cúspide de la organización jurisdiccional, y al mismo tiempo valor subalterno y ancilar con respecto a las genuinas fuentes de creación del derecho. Obviamente se trata de una visión preconstitucional y de muy problemático encaje en los esquemas de una Constitución que se pretende normativa y en la que se crea, por ende, una jurisdicción de nuevo cuño especializada en su defensa. El intento de enfrentar ese problema, así como el aún más espinoso de aclarar la relación entre un Tribunal dicho Supremo y otro Constitucional, está en la propia Constitución: en el art. 123.1, en el que el carácter de supremo se intenta delimitar por referencia negativa a todo aquello que no implique "garantías constitucionales»; y en el art. 164.1, que es un verdadero tour de force con respecto al valor de la jurisprudencia del Tribunal Constitucional en un escenario por completo diverso al que trasluce el Código Civil. Para empezar, las sentencias, todas las sentencias del TC, se publican en el Boletín Oficial acompañadas de los votos particulares, si los hubiere. Y para seguir: las que declaren la inconstitucionalidad de una ley, así como todas aquellas que no se limiten a la estimación subjetiva de un derecho — prosigue el citado art. 164.1 - tienen plenos efectos frente a todos.

En lo que se refiere al primer problema, y no obstante la presencia episódica de una versión a la española de la famosa "guerra de Cortes», el despliegue de la experiencia jurídica acumulada durante estos años ha demostrado que, como se ha dicho gráficamente, supremo solo hay uno, pero no es el que se llama así (Rubio Llorente, 1994). Y es lógico que así sea, puesto que quien tiene el poder de decir la última palabra anulando o corrigiendo resoluciones anteriores con efectos jurídicos precisos es el que ocupa la cúspide de la 
jerarquía, por más que esta aparezca desdoblada en una jurisdicción ordinaria y otra constitucional. Constitucionales lo son las dos y a todos los jueces y los magistrados que las componen les corresponde interpretar la Constitución. Pero supremo intérprete de ella solo hay uno, el Tribunal Constitucional, como así lo dice el art. 1 de su Ley Orgánica, lo que determina su superior posición en el conjunto.

Y en lo que se refiere a la segunda cuestión, la del valor de la jurisprudencia constitucional, ya desde el principio se advirtió de lo dificultoso que resultaba identificar resoluciones del TC que se limitaran a la estimación subjetiva de un derecho (por todos, Alonso García, 1988). Cualquier sentencia contiene razones para decidir y consideraciones al pasar que forman un cuerpo de doctrina y desbordan necesariamente lo que pueda venir considerado como el efecto en corto de la resolución. Pero con independencia del debate teórico sobre lo que el constituyente pudiera tener in mente al utilizar semejante expresión, lo cierto es que en 1985, cuando en España se aprobó la Ley Orgánica del Poder Judicial, sustituyendo una legislación del siglo XIX para adaptar la actuación de este a las exigencias del nuevo escenario constitucional, el art. 5.1 de la misma supuso un giro copernicano con respecto al valor de la jurisprudencia constitucional, su engarce con la jurisdicción ordinaria, y el propio carácter de la Constitución como el marco referencial para la interpretación del ordenamiento jurídico en su conjunto ${ }^{12}$. El precepto actúa como un recordatorio del valor normativo de la Constitución y de su cualidad de lex superior. Pero no es esto lo más relevante. Lo que interesa es que en esa disposición se ubica lo que es quizá el único mandato dirigido a jueces y magistrados, es decir a todos cuantos tienen atribuida en España la función jurisdiccional, sobre el cómo de la interpretación de la ley. La sujeción con carácter exclusivo al imperio de ella (art. 117.1 de la Constitución) resulta, como es sabido, la clave de bóveda sobre la que se erige la independencia del juez en el Estado constitucional. Para cuadrar el círculo que representa el desplazamiento de la ley por la Constitución, y la simultánea atribución al TC en régimen de monopolio de la facultad de extraer de ello las pertinentes consecuencias velando por la constitucionalidad de la ley, lo que se le pide al juez es que tome la Constitución como la plataforma necesaria para la interpretación del derecho; toda la

12 Vale la pena reproducir dicho art. 5.1 de la LOPJ para captar en toda su extensión sus implicaciones: «La Constitución es la norma suprema del ordenamiento jurídico, y vincula a todos los Jueces y Tribunales, quienes interpretarán y aplicarán las leyes y los reglamentos según los preceptos y principios constitucionales, conforme a la interpretación de los mismos que resulte de las resoluciones dictadas por el Tribunal Constitucional en todo tipo de procesos». 
Constitución, con sus preceptos y sus principios, y todo el derecho, si bien las contradicciones que el juez pueda detectar entre la Ley y la Constitución habrá de resolverlas planteando la cuestión de inconstitucionalidad ante el TC (y convenciéndole de la relevancia que su duda tiene para la resolución del caso), salvo que se trate de una ley anterior a la Constitución, en cuyo caso podría el juez dejar de aplicarla por sí mismo con efectos inter partes. Pero lo decisivo a nuestros efectos es que aquella plataforma no se colma con la llamada en seco a la Constitución, sino con la apelación a la jurisprudencia establecida por el TC «a través de las resoluciones dictadas en todo tipo de procesos».

Las reglas del juego y el deber ser de la tarea de interpretar en el sistema constitucional lucen claras y esplendorosas, aun cuando no faltan en ellas zonas sombrías: ¿qué ocurre cuando no se detecta una línea continua en los pronunciamientos del intérprete supremo? ¿Y si los pronunciamientos son contradictorios? ¿Con respecto a qué parte de las resoluciones se postula el efecto irradiante? ¿Cuentan los votos particulares? Y sobre todo y de manera crucial: ¿y si el juez se aparta de la línea de interpretación establecida, bien porque la desconoce, bien porque no la identifica correctamente, o bien porque considera que el vínculo con la ley supone para él un blindaje de más fuerte hechura que la llamada genérica a un modo de interpretar que puede considerar erróneo en el caso concreto? Se nos dirá que los recursos y la organización escalonada de lo jurisdiccional actúan normalmente como antídotos contra tales o semejantes "puntos ciegos». Y seguramente es cierto, aunque no los elimina, ni impide que el de la fuerza directriz o «descendente» de la jurisprudencia del intérprete supremo, además de un desafío de carácter práctico, continúe dando lugar en el Estado constitucional de derecho a «trampantojos» teóricos causados por postulados cuyo cumplimiento no acaban de cumplirse cabalmente.

\section{A MODO DE CONCLUSIÓN}

En las páginas anteriores hemos pasado revista a una serie de componentes del sistema de defensa de la constitucionalidad en México y en España que presentan ciertos «claroscuros» o «zonas grises». Como decíamos al comienzo, podemos identificar como tales aquellas que son producto de unas normas reguladoras o unas prácticas aplicativas manifiestamente mejorables. Por supuesto que el repertorio no está completo. Bajo el mismo criterio director, dejamos para otra ocasión un análisis detenido de los desafíos que hoy se le presentan al Estado constitucional comprometido con la defensa supranacional de los derechos y abierto al influjo procedente de intérpretes situados más allá de sus fronteras. Con los que hemos enumerado basta, sin embargo, para 
entender que el componente normativo de la democracia constitucional, por más «ingeniería» sofisticada que pueda requerir, también necesita mantener vivo el compromiso de rectificar lo que no funciona de manera satisfactoria. Reivindicar que la vida de las instituciones responda fielmente a los principios que la Constitución estableció en aras del eficaz cumplimiento de sus cometidos, no debería pasar nunca por melancólica invocación de un inasible perfeccionismo, sino por juiciosa llamada de atención sobre lo peligroso que puede resultar, para la vida de la Constitución, conformarse con diseños normativos, o transigir con prácticas, que resultan manifiestamente mejorables.

\section{Bibliografía}

Alonso García, E. (1988). La jurisprudencia constitucional. Revista del Centro de Estudios Constitucionales, 1, 173-209.

Aragón Reyes, M. (2019). «El futuro de la justicia constitucional». Anuario Iberoamericano de Justicia Constitucional, 23 (1), 11-41. Disponible en: https://doi. org/10.18042/cepc/aijc.23.01.

Astudillo, C. (2010). El nombramiento de los Ministros de la Suprema Corte de Justicia en México. En A. von Bogdandy, E. Ferrer MacGregor y M. Morales Antoniazzi (coords.). La justicia constitucional y su internacionalización. ¿Hacia un ius constitucionale commune en America Latina? México: Instituto de Investigaciones Jurídicas.

Astudillo, C. y Estrada Marún, J. A. (2019). Nombramiento de ministros de la Suprema Corte de Justicia de la Nación en el contexto de los modelos de designación en el Derecho Comparado. México: Porrúa.

Cabrera Acevedo, L. (1990). La jurisprudencia de la Suprema Corte de Justicia y aspectos de sus facultades discrecionales. En J. F. Smith (coord.). Derecho Constitucional Comparado México-Estados Unidos, t. 1 (pp. 477-494). México: Universidad Nacional Autónoma de México.

Castellanos Madrazo, F. (2014). La sentencia interpretativa en la jurisprudencia de la Suprema Corte de Justicia de la Nación. Revista del Instituto de la Judicatura Federal, 38, 245-274.

Comisión de Venecia (2017). Compilation of Venice Commission Opinions, Reports and Studies in Constitutional Justice. Disponible en: www.venice.coe.inf.

Cossío Díaz, José Ramón (2011). Sistemas y modelos de control constitucional en México. México: Instituto de Investigaciones Jurídicas.

Estrada Marún, J. A. (2017). La designación de los magistrados del Tribunal Constitucional en España. Madrid: Marcial Pons.

Fernández Farreres, G. (2015). Sobre la designación de los magistrados constitucionales: una propuesta de reforma constitucional. Revista Española de Derecho Constitucional, 105, 13-49. Disponible en: https://doi.org/10.18042/cepc/ redc.105.01. 
Ferrer McGregor, E. (2000). La acción constitucional de amparo en México y en España. México: Porrúa.

Ferreres Comella, V. (2011), Una defensa del modelo europeo de control de constitucionalidad. Madrid: Marcial Pons.

López Benítez, L. M. (2017). Sistemas de jurisprudencia en el juicio de amparo. En E. Ferrer MacGregor y A. Herrera García (eds.). El juicio de Amparo en el centenario de la Constitución mexicana de 1917. Pasado, presente y futuro, t. II. México: Instituto de Investigaciones Jurídicas.

Morales Arroyo, J. M. et al. (2014). Recurso de Amparo, derechos fundamentales y trascendencia constitucional. El camino hacia la objetivación del amparo constitucional en España. Cizur Menor: Aranzadi.

Nogueira Alcalá, H. (2019). El Tribunal Constitucional chileno y perspectivas comparativas con tribunales constitucionales latinoamericanos. Valencia: Tirant.

Rubio Llorente, F. (1994). Supremo no hay más que uno, pero no es el verdadero. El Pais, 2 de septiembre de 1994. Disponible en: https://elpais.com/diario/1994/02/09/opinión/760748409_850215.html.

Serra Cristóbal, R. (2011). La selección de jueces en Estados Unidos. Cizur Menor: Aranzadi.

Soberanes Fernández, J. (1987). Sobre el origen de la Suprema Corte de Justicia de la Nación. México: Instituto de Investigaciones Jurídicas.

Suárez Ávila, A. A. (2017). Usos e interpretación de la facultad de atracción en el juicio de amparo por la SCJN. En E. Ferrer MacGregor y A. Herrera García (eds.). El juicio de Amparo en el centenario de la Constitución mexicana de 1917. Pasado, presente y futuro, $t$. I. México: Instituto de Investigaciones Jurídicas.

Urías Menéndez, J. (2010). El Tribunal Constitucional ante la participación autonómica en el nombramiento de sus miembros. Revista d'Estudis Autonomics $i$ Federals, 10, 207-244.

\section{Tesis jurisprudenciales y acuerdos legislativos de México}

Jurisprudencia 2a./J. 11/2002, Semanario Judicial de la Federación y su Gaceta, novena época, t. XV, febrero de 2002, p. 41.

Tesis de jurisprudencia IX.10.71 K, Semanario Judicial de la Federación y su Gaceta, Novena Época, t. XVIII, octubre de 2003, p. 1039.

Tesis de jurisprudencia 2a. XXIII/2019 (10a.), Gaceta del Semanario Judicial de la Federación, libro 65, abril de 2019, Tomo II, p. 1342.

Cámara de Senadores del Congreso de la Unión (2015, 18 de noviembre). Acuerdo de la Junta Directiva de la Comisión de Justicia por el que se establece el procedimiento para la comparecencia y dictaminación de las ternas presentadas por el Ejecutivo Federal para la elección de dos Ministros de la Suprema Corte de Justicia de la Nación. 
Cámara de Senadores del Congreso de la Unión (2018, 13 de diciembre). Acuerdo de la Mesa Directiva por el que se establece el procedimiento para la elección de Ministra o de Ministro de la Suprema Corte de Justicia de la Nación.

Cámara de Senadores del Congreso de la Unión (2019, 8 de febrero). Acuerdo de la Comisión de Justicia por el que se establece el procedimiento para la competencia de las personas que integran la terna presentada por el titular del ejecutivo federal para la elección de una Ministra de la Suprema Corte de Justicia de la Nación con motivo de la conclusión del cargo de la Ministra Margarita Luna Ramos.

Jurisprudencia del TC español y del TEDH

STC $108 / 1986$.

STC 49/2008.

STC $101 / 2008$.

TEDH, caso Arribas Antón contra España (Demanda 16563/11), sentencia de 20 de enero de 2015 de la Sección Tercera. 
ANEXO

Tabla 1. Relación de asuntos resueltos por la SCJN en 2019 desglosados por competencias y articulaciones orgánicas de la Corte*

\begin{tabular}{|c|c|c|c|c|}
\hline Tipos de asuntos & Pleno & $\begin{array}{l}\text { Primera } \\
\text { sala }\end{array}$ & $\begin{array}{l}\text { Segunda } \\
\text { sala }\end{array}$ & Total \\
\hline Recursos de reclamación & 2 & 1.414 & 1.444 & 2.860 \\
\hline Amparos directos en revisión & 2 & 734 & 519 & 1.255 \\
\hline Amparos en revisión & 4 & 241 & 333 & 578 \\
\hline Contradicciones de tesis & 36 & 172 & 242 & 450 \\
\hline Conflictos competenciales & 0 & 95 & 295 & 390 \\
\hline Controversias constitucionales & 114 & 107 & 76 & 297 \\
\hline $\begin{array}{l}\text { Solicitudes de ejercicio de la facultad de } \\
\text { atracción }\end{array}$ & 0 & 100 & 124 & 224 \\
\hline Incidentes de inejecución de sentencia & 112 & 48 & 31 & 191 \\
\hline $\begin{array}{l}\text { Recursos de reclamación en acciones de } \\
\text { inconstitucionalidad o en controversias } \\
\text { constitucionales }\end{array}$ & 0 & 94 & 78 & 172 \\
\hline Solicitudes de reasunción de competencia & 0 & 11 & 141 & 152 \\
\hline Acciones de inconstitucionalidad & 134 & 11 & 4 & 149 \\
\hline Revisiones administrativas & 4 & 65 & 44 & 113 \\
\hline Impedimentos & 3 & 20 & 9 & 32 \\
\hline Amparos directos & 0 & 9 & 18 & 27 \\
\hline $\begin{array}{l}\text { Recursos de inconformidad previstos en las } \\
\text { fracciones I a III del artículo } 201 \text { de la Ley } \\
\text { de Amparo }\end{array}$ & 1 & 10 & 16 & 27 \\
\hline Quejas & 0 & 3 & 12 & 15 \\
\hline $\begin{array}{l}\text { Incidentes de inejecución derivados de } \\
\text { denuncia de repetición del acto reclamado }\end{array}$ & 0 & 7 & 6 & 13 \\
\hline Incidentes de cumplimiento sustituto & 3 & 5 & 4 & 12 \\
\hline $\begin{array}{l}\text { Incidentes de incumplimiento de sentencia } \\
\text { derivado de controversia constitucional }\end{array}$ & 0 & 0 & 12 & 12 \\
\hline Recursos de apelación & 0 & 5 & 4 & 9 \\
\hline Solicitudes de sustitución de jurisprudencia & 1 & 2 & 5 & 8 \\
\hline $\begin{array}{l}\text { Quejas en controversias constitucionales y } \\
\text { en acciones de inconstitucionalidad }\end{array}$ & 1 & 3 & 3 & 7 \\
\hline
\end{tabular}




\begin{tabular}{|c|c|c|c|c|}
\hline Tipos de asuntos & Pleno & $\begin{array}{c}\text { Primera } \\
\text { sala }\end{array}$ & $\begin{array}{l}\text { Segunda } \\
\text { sala }\end{array}$ & Total \\
\hline $\begin{array}{l}\text { Incidentes derivados de juicios ordinarios } \\
\text { federales }\end{array}$ & 0 & 2 & 4 & 6 \\
\hline $\begin{array}{l}\text { Consultas a trámite previstas en el párrafo } \\
\text { segundo de la fracción II del artículo } 14 \\
\text { de la Ley Orgánica del Poder Judicial de la } \\
\text { Federación }\end{array}$ & 5 & 0 & 0 & 5 \\
\hline $\begin{array}{l}\text { Recursos de inconformidad previstos en la } \\
\text { fracción IV del artículo } 201 \text { de la Ley de } \\
\text { Amparo }\end{array}$ & 1 & 0 & 4 & 5 \\
\hline Juicios ordinarios federales & 0 & 1 & 2 & 3 \\
\hline $\begin{array}{l}\text { Revisiones administrativas (Ley } \\
\text { Federal de Procedimiento Contencioso } \\
\text { Administrativo) }\end{array}$ & 0 & 0 & 3 & 3 \\
\hline $\begin{array}{l}\text { Incidentes de inejecución derivados de } \\
\text { incidente de cumplimiento sustituto }\end{array}$ & 2 & 0 & 0 & 2 \\
\hline $\begin{array}{l}\text { Declaratoria general de } \\
\text { inconstitucionalidad }\end{array}$ & 1 & 0 & 0 & 1 \\
\hline $\begin{array}{l}\text { Denuncia de incumplimiento por } \\
\text { aplicación de normas o actos declarados } \\
\text { inválidos en la controversia constitucional }\end{array}$ & 0 & 1 & 0 & 1 \\
\hline $\begin{array}{l}\text { Incidente de falsedad de documentos de la } \\
\text { controversia constitucional }\end{array}$ & 1 & 0 & 0 & 1 \\
\hline Inconformidad & 0 & 1 & 0 & 1 \\
\hline $\begin{array}{l}\text { Juicio sobre cumplimiento de los convenios } \\
\text { de coordinación fiscal }\end{array}$ & 1 & 0 & 0 & 1 \\
\hline $\begin{array}{l}\text { Procedimiento de responsabilidad } \\
\text { administrativa }\end{array}$ & 1 & 0 & 0 & 1 \\
\hline $\begin{array}{l}\text { Recurso de inconformidad derivado } \\
\text { de procedimiento de responsabilidad } \\
\text { administrativa }\end{array}$ & 0 & & & \\
\hline Varios & 0 & 0 & 1 & 1 \\
\hline TOTAL DE ASUNTOS RESUELTOS & 429 & 3.161 & 3.435 & 7.025 \\
\hline
\end{tabular}

* La información contenida en esta tabla forma parte del primer informe del ministro presidente de la SCJN, Arturo Zaldívar Lelo de Larrea ${ }^{13}$.

13 El informe de actividades del año 2019 completo puede ser consultado en: https:// www.scjn.gob.mx/primerinformezaldivar/pdf/informe-labores-2019.pdf. 
Tabla 2. Relación de asuntos resueltos por el TC en 2019 desglosados por competencias y articulaciones orgánicas del tribunal*

\begin{tabular}{|c|c|c|c|c|}
\hline Tipos de proceso & Pleno & Sala I & Sala II & Total \\
\hline Recursosde inconstitucionalidad & 34 & 0 & 0 & 34 \\
\hline Cuestiones de inconstitucionalidad & 31 & 2 & 4 & 37 \\
\hline Conflictos positivos de competencia & 4 & 0 & 0 & 4 \\
\hline Conflictos negativos de competencia & 1 & 0 & 0 & 1 \\
\hline Conflictos entre órganos constitucionales & 0 & 0 & 0 & 0 \\
\hline $\begin{array}{l}\text { Conflictos en defensa de la autonomía } \\
\text { local }\end{array}$ & 0 & 0 & 0 & 0 \\
\hline $\begin{array}{l}\text { Impugnación de disposiciones de las } \\
\text { comunidades autónomas }\end{array}$ & 3 & 0 & 0 & 3 \\
\hline $\begin{array}{l}\text { Requerimientos sobre la } \\
\text { constitucionalidad de los tratados } \\
\text { internacionales }\end{array}$ & 0 & 0 & 0 & 0 \\
\hline $\begin{array}{l}\text { Cuestión prejudicial sobre normas forales } \\
\text { fiscales }\end{array}$ & 1 & 0 & 0 & 1 \\
\hline Amparos & 34 & 3.365 & 3.103 & 6.495 \\
\hline TOTAL & 74 & 3.367 & 3.107 & 6.575 \\
\hline
\end{tabular}

* Esta información forma parte del informe de estadísticas jurisdiccionales del TC correspondiente al año $2019^{14}$.

14 La estadística completa puede ser consultada en: http://www.tribunalconstitucional. es/es/memorias/Estadisticas/memo\%202019\%20anexo\%2003\%20estadisticas_V6_ LPS.pdf. 